\title{
Cultural/Customs and Traditional Belief Systems That Impact Participation of Females in \\ Sports/Games and Physical Activities. The Case of Colleges of Education in Northern Region-Ghana
}

\author{
Zakaria Shanunu ${ }^{1}$, Adams Sulemana Achanso ${ }^{2}$, Ibrahim Mohammed Gadafi ${ }^{3}$, Iddrisu Sulemana ${ }^{4}$ \\ ${ }^{1}$ University for Development studies, faculty of Communication and Culture-Tamale, \\ ${ }^{2}$ University for Development studies, faculty of Sustainable Development studies- Tamale, \\ ${ }^{3}$ University for Development studies, faculty of Communication and Culture-Tamale, and, \\ ${ }^{4}$ Tamale College of Education- Tamale.
}

\begin{abstract}
Culture and sport are frequently seen as having societal consequences. The participation of women in sports and physical activities is influenced in a variety of ways. Female participation in Sports/games and physical activities could have a significant positive impact on an individual's physical, cultural, traditional/customs mental, and social well-being. The purpose of this research is to look at some of the Cultural/Customs and Traditional belief systems that influence women's engagement in physical activities and games in Northern region colleges of education. The researchers employed a survey research approach to study about the cultural/customs and traditional belief systems that influence female engagement in sports/games and physical activities. Female students from the four colleges of education in the Northern region (Bagabaga College, E.P College - Bimbilla, Tamale College, and St' Vincent College-Yendi) were the target population. The study identified some key findings of Cultural/Customs and Traditional belief practice which include, women's access to information is limited by strict customs observation, myths, place of the woman is in the kitchen, curses and taboos based on effects on their reproductive organs, and women lose their femininity through active participation in sports, female genital mutilation, and women cleansing are some of the belief systems that contribute to women's low participation in sports/games and physical activity. The study also identified other factors such as, Religious Beliefs/Norms, gender limitations, sociological and physiological variables that influence female engagement in sports/games and physical activities. It is recommended that the use of cultural enlightenment educational programmes that will demystify all traditional/customs and cultural belief systems and biases against female participation in sporting, games and physical activities in our communities. Use of Legislation to promote Cultural/Customs and Traditional physical activities in schools.
\end{abstract}

Keywords: Sports, Female, Culture, Customs, Traditional, Belief systems, Physical activity.

\section{INTRODUCTION}

$\mathrm{C}$ ulture and Sports/games and physical activity are widely perceived to generate social impacts. Female participation in sport and games activity is influenced in a multitude of ways. What motivates females to participate changes over time and factors influencing participation have individual, cultural beliefs systems and social origins. Program designers and providers can leverage the influence of people and environments to help motivate females to participate in sport and games programs. In the first Olympic games of $776 \mathrm{BC}$ in Ancient Greece women were not permitted to be spectators on Mount Olympus (Wuest and Bucher 2001). They also indicated that females who had the audacity to peep and where caught lost their lives" (p. 128). Both males and females in schools often engage themselves in various sporting activities of their choice in order to develop their motor skills and general well-being. Apart from the fact that participating in sports is beneficial to all round development of female students, it also enhances unity among schools in the communities. Participating in sports helps to transcend cultural differences and unite people and above all it arouses the interest of students.

\section{Objectives}

The world is becoming a global village and within many professions, including physical education, culture and sports, individuals have multiple opportunities to work and socialize with people from different ethnic, cultures, lifestyles and religious backgrounds. Due to the increasing cultural diversity, it is important for educational professionals to understand how cultural/customs, traditional and social factors of different ethnic groups may influence a person from participating in sports/games and physical activity. The aim of this study is to examine some of the Cultural/Customs and Traditional beliefs systems have on women's participation in physical activities and games/sports in Colleges of Education in Northern Region- Ghana.

\section{LITERATURE SPORT AND CULTURE ARE INTERTWINED}

Sport is a broad and ambiguous phrase that refers to a variety of activities (Chen et al, 2017). We include any type of sport, games, physical activity, and formal exercise taken place in 
colleges of education in our study, as well as the health advantages of sports, but we omit other forms of physical activity, such as walking or cycling to work, using the stairs instead of the elevator, and gardening. Sports involvement is a vehicle for bringing people of all cultures and creeds together, as well as an outlet for bringing individuals of various genders, ages, and religious backgrounds together (Rowe, 2014).

Culture is taught, shared, and passed down over generations, and it is represented in a group's values, beliefs, conventions, practices and patterns of communication, familiar roles, and other social regularities, according to social scientists (Birrell \& Cole, 2016). Culture, according to Duxbury et al (2015), is also dynamic and adaptable. It arose from early hominids' attempts to optimize the possibility for collective success in the face of environmental difficulties, and it persists today in cultural groupings as a conflict between preserving shared values and standards while adapting to forces of change both within and outside the group.

According to Ugwueze (2014), certain societies assign specific responsibilities to men and women.

Women in our traditional and cultural societies are mostly educated at home to become good housewives and mothers. (Ugwueze, 2014). Men, on the other hand, like to live in the open air. While women are taught to cook, wash dishes, scrub bathrooms, and do primarily domestic tasks, men are taught to engage in more dangerous outside activities he added. Ugwueze (2014) described it this way: "The women's social club was created for stay-at-home and prospective brides, and mothers". They are not allowed to participate in strenuous and traditional activities such as tree climbing or traditional sports such as wrestling "He went on to say (p. 44). Despite the immense benefits derived from participation in sports and games activities, this societal demand on women prevents the vast majority of females from treating competitive sport and games as serious business. Over the previous three centuries, spontaneous physical folk play and game competitions have evolved into formalized, planned activities, and the love of the game (the "amour" at the foundation of "amateurism") has gradually given way to professional spectator sports (Cashmore et al., 2015).

The relatively modest remuneration of sportspeople (mostly male) that followed the decline of the class-based, aristocratic ideal of the "sporting gentleman" involved first the payment of expenses and lost wages by those who had to exchange their Labour power to survive; then payment for play that was often insufficient to provide a living wage; and, finally, reasonable returns for "sports work" (Cashmore et al., 2015). However, much like in other areas of the Labour market, where pay disparity developed between co-workers in the same business and between industries, sports' increasing cultural/custom and traditional "selling ability" has generated "superstars" rewarded at exceptional amounts. Michael Jordan, an African American basketball player, and Marian Jones, a track and field athlete, are two prominent instances of celebrity athletes who are among the world's most wellknown people. The restructuring of the athletic Labour market into a small group of "super rich," a larger but still small group of modestly compensated professionals, and a large number of aspiring professional athletes with little chance of success reflects a "structure of culture" in sports that now closely aligns it with the broader entertainment industries.

Even people who do not make a living from sports are part of a vast sports business that provides facilities, apparel, training, and equipment. Sponsors, advertisers, media companies, sports agencies, peak sports organizations, management, equipment and clothing manufacturers, privately and publicly funded sports educators, administrative and training bodies, and research scientists are all part of the "industrial" engine that produces professional athletes. Modern sports and culture rely on systematic planning, design, and operation while preserving a key symbolic aspect of a spontaneous culture of play. In certain regions of the nation, the traditional insinuations that a woman's place is in the kitchen are still prevalent. However, it is a well-known truth in Ghana that the female soccer team (Black Queens) was the first to qualify for the 1999 World Cup in the United States. Women have won medals in highly ranked sporting disciplines, from participation to administration.

Sports are thus both a symptom and a cause of a larger sociocultural shift, as highly localized cultural practices of spatially fixed settlements such as villages and small towns have become concentrated in large urban centers, only to be redistributed in mediated form through the dissemination of images and sounds. Through the sports press, public service and commercial television, this symbolic sports communication has become a crucial method of constructing national cultural identity. International sports events mediated by the media provide exceptional chances for internal and external nation representations, a fundamentally ideological practice that requires thorough sociological examination, not least because of its seeming innocence. This demonstrates how mediated sports culture may pique the interest of sports sociologists, who have found its terrain to be fertile ground for exploring social connections, economics, politics, ideology, and culture both within and outside of the sports world.

\section{Sport And Games Have A Social Impact}

Participation in sports and fitness has been shown to provide a variety of social benefits. The best evidence is in the area of health benefits that prevent or decrease physical and mental health issues while also lowering health-care expenditures. Physical health is supported by greater evidence than mental health (Bernstein, 2013). Sports injuries, which are more often linked with young people and typically minor injuries, have certain unfavorable health consequences. Positive health advantages are beneficial to the entire community, but they are especially essential to the elderly. According to Bernstein, (2013) there is much evidence of the favourable impact of sport and exercise on educational outcomes, including psychological, cultural/traditional, and cognitive advantages. 
Sport, games, and exercise, in turn, have been demonstrated to improve a variety of end outcomes, including scholastic achievement.

A few contradictory research have found detrimental impacts of sports and games involvement on the educational achievement of particular student groups (Roche 2017). According to several research, sport has many effects at the same time, making it a very cost-effective intervention (Roche 2017). Greater physical competence, higher cognitive skills, better social skills, trust and reciprocity, and affiliation with social ideals are all common linkages between sport and various social consequences (Roche 2017). These aid in the reduction of risk factors and the stimulation of a favourable response to protective factors.

\section{Physical Fitness}

Sport and exercise have been shown to offer preventive and therapeutic effects in adults, adolescents, women, and children, according to a research by Hazel Maxwell, (2010). Although there is strong scientific evidence of a good link between sport and physical health, there are certain dangers of negative consequences, such as accidents, injury, and undetected heart illnesses (Hazel Maxwell, 2010). Although there is widespread support for the notion that getting the inactive majority to increase their levels of sport, exercise, and physical activity would have the greatest social impact in terms of health gain, Carroll et al (2018) agree that the doseresponse relationship is complex and varies by disease, there is widespread support for the notion that getting the inactive majority to increase their levels of sport, exercise, and physical activity would have the greatest social impact in terms of health gain. Many studies show significant physical health benefits with at least moderate intensity activity, and there is typically a positive linear association between increased activity levels and increased gains in health and mortality, according to Cox (2014).

Participation in sports and exercise appears to promote beneficial health behaviour among a variety of populations, according to numerous researches (Whannel, 2013). This can lower the risk of a variety of diseases and disorders. Physical exercise had a substantial negative influence on smoking development among teenagers who participated in at least one team sport, according to Birrell \& McDonald (2016). Active adolescents smoke less than inactive adolescents, according to Birrell \& Cole (2014). Miller, et al. (2011) agreed that a sports-based intervention in the Dominican Republic enhanced HIV-related awareness among adolescents.

\section{Mental Well-Being}

The amount of data on the effects of sport, games, and exercise on mental health is far less than that on physical health. However, research indicates that sport, gaming, and exercise can have beneficial preventative and therapeutic effects for women's mental health and wellness (Walseth, 2016). Sport and exercise have been shown to lower the chance of acquiring mental disorders and to aid in the treatment of some mental illnesses (Crawford, 2014). Furthermore, unlike domestic or work-based physical activity, organized sport, games, and exercise/recreation include a social component that can help combat feelings of isolation, which is often a hallmark of poor mental health (Martin, \& Miller 2015).

\section{Women And Exercise}

Regular exercise has several health advantages, including decreasing blood pressure, lowering cholesterol, avoiding cardiovascular disease, preventing diabetes, enhancing mood and cognitive function, and lowering mortality. Due to their unique combination of hormones and health concerns, women's advantages are amplified (Women's Sport and Fitness Foundation 2011).

"Many of the health concerns that women encounter can be significantly improved with regular exercise. It's one of the most effective preventative measures known, and it should be encouraged beginning in childhood and continuing throughout life," says the author (Women's Sport and Fitness Foundation 2011).

The organization also identified four ways that exercise and physical activities helps women, regardless of their age:

Women who participate in sports and leisure activities had higher levels of confidence, self-esteem, and pride in their physical and social behaviour than inactive women. Half of all females who participate in sports have greater self-esteem and are less depressed than the general population. "Boys are more interested in sports than girls" is a fallacy (Palmer, 2015). We know that when females are young, they are equally as interested in sports as boys (Wuest \& Bucher, 2001)

From an observational standpoint by Angela, (2001) girls drop out of sports at a rate two times higher than boys due to a lack of opportunity, lack of peer group support when they do play sports, and a lack of encouragement. According to research, girls who participate in athletics are less likely to use drugs, are less likely to become pregnant, and are more likely to graduate from high school than girls who do not (Angela, 2001). Many women from culturally, traditionally and linguistically diverse backgrounds, particularly Muslim women, are significantly less involved in sport and recreation activities in Western nations than the general female population, according to research (Women's Sport and Fitness Foundation, 2011; Cortis, Sawrikar, \& Muir, 2016). There are a number of reasons for this "under-representation," according to Hanlon \& Coleman, (2016); Palmer, (2015); Sfeir, (2010); Walseth, (2006), including non-inclusive practices of sport organizations, restrictive community attitudes and values, lack of appropriate venues and/or opportunities that allow culturally appropriate clothing to be worn, and scarcity of female-only sporting environments. Specific religious restrictions have also been highlighted as a source of difficulty for Islamic immigrants living in non- 
Islamic nations, according to research (Hargreaves 2015 \& Kahan, 2013).

Islamic teachings, on the other hand, do not ban Muslim women from engaging in physical exercise (Kahan, 2013; Sfeir, 2010), with swimming, archery, and horseback riding being particularly encouraged. Women participate in competitive sport in many nations and have achieved success and achievements at all levels of sport, including top athletic contests such as the Olympics (Kahan, 2013). Physical exercise is typically viewed favourable by women who identify with religion as a form of identification, according to evidence (Walseth, 2016). According to Coalter, (2017; Coffe \& Geys, (2015), sport has the ability to build positive social capital in the form of trust, openness, and respect for various persons and groups, which may help communities cooperate more effectively and enhance social cohesion.

\section{Exercise Can Help You Deal With Mood Fluctuations Caused By Hormones.}

Women live with a fluctuating amount of estrogen and progesterone from the first menstrual cycle until menopause, according to Vera (2014), which affects their reproductive patterns as well as their brain chemistry and moods. When estrogen levels fall, as they do before and during a woman's period or as she approaches menopause, women lose a natural source of serotonin, the "feel good" brain chemical. This makes individuals more prone to mood swings, sadness, and anxiety attacks, which are common signs of severe premenstrual syndrome or postpartum depression. Exercise releases endorphins, another mood regulator, which counteracts hormonally induced mood fluctuations. Endorphins, sometimes known as the "runner's high," make you feel pleased and calm after a workout. "It's our bodies' method of replacing one fading natural substance with another," says the author (Walseth, 2016). "For some women, this may minimize or eliminate the need for anti-depressant medicines that raise serotonin levels (Angela et al., 2001) "Exercise can boost mood even after menopause, when estrogen levels have permanently decreased. In a study of 60 women suffering from postmenopausal anxiety and depression, Vera (2014) discovered that those who exercised saw an 18 to 22 percent improvement in symptoms, whereas those who did not exercise saw no change.

\section{Exercising Helps You Maintain A Healthy Weight}

Men and women both gain weight as they become older, but women have unique problems owing to their physiological makeup. Pregnancy weight gain can persist in younger women for a long time after delivery (Vera 2014). The body then redistributes fat cells to the belly when middle-aged women lose estrogen during menopause, making weight reduction more difficult (Vera 2014). Because muscle burns more calories than fat, when women's muscle mass diminishes with age, they may find it difficult to maintain or lose weight (Shanunu 2019).
These variables may be countered by exercise, which helps women maintain and grow lean muscle mass, making them seem and feel smaller (Klafs, et al 2013). Exercising also helps to burn calories that might otherwise be stored as fat. In a 20-year study of 3,500 men and women by Northwestern University researchers, all individuals gained weight as they grew older, but those who exercised gained significantly less (Klafs et al 2013). Women, in particular, benefited, gaining 13 pounds less on average than inactive women, according to the researchers.

\section{What Role Does Culture/Customs Have In Shaping Health Beliefs?}

Every person wishes to be acknowledged as a member of a certain cultural group. Inevitably, everyone belongs to one of two groups, and when he adheres to a certain way of life, he is easily identifiable as a member of that group. We become cultural creatures as a result of our way of life (Diawuo \& Issifu 2015). Healthcare companies and patients can benefit from cultural competency. It leads to more patient participation and engagement, as well as enhanced respect and understanding, which can lead to improved patient safety.

Health beliefs exist in all cultures to explain what causes disease, how it may be treated or healed, and who should be engaged in the process (Throsby 2011). The degree to which patients believe patient education is culturally relevant to them can have a significant impact on how they receive information and how eager they are to apply it. Medical therapies that battle germs or utilize advanced technology to detect and cure disease are advocated in Western industrialized cultures such as the United States, which regard disease as a result of natural scientific events (Osei, 2012). Some African civilizations, like Ghana, believe that sickness is caused by supernatural powers and encourage prayer or other spiritual therapies to counteract the alleged disfavour of strong spirits (Osei, 2012). Patient compliance is heavily influenced by cultural factors.

According to research, a group of Cambodian people with little formal education made significant attempts to adhere to therapy, but did so in a way that was consistent with their fundamental understanding of how medications and the human body function (Idowu, 2016).

Health is seen as the consequence of a harmonic balance between the poles of heat and cold that regulate physiological processes in Vietnamese culture, where mystical beliefs explain physical and mental disease (Appiah-Opoku 2007). Vietnamese people are hesitant to embrace Western mental health therapy and therapies, especially if self-disclosure is required (NZMCH 2016).

However, if confidence has been established, it is feasible to accept aid.

\section{Physical Exercise And Culture/Customs}

People give a variety of explanations for their lack of exercise, one of which being cultural attitudes. Whether or not a certain 
physical activity is linked with a particular race may have an impact on how frequently different ethnic groups participate in it. According to Birrell and Cole (2014), in a study conducted by behavioural and social scientists at the Alpert Medical School and the University of Alabama at Birmingham, black adolescents were asked to rate 42 physical activities as "mostly a black thing," "mostly a white thing," or "equally a black and white thing."

Basketball, soccer, sports, volleyball, and yoga were all investigated to see whether any of the activities generated a racial identity from the teenagers. According to the survey, the majority of the activities were assessed as "equally a black and white thing." A majority of the participants did not perceive any of the activities to be "primarily a black thing."

There was a data analysis for connections between racial perceptions of physical activities and the participants' health, according to Birrell and Cole (2014). Participants who said "primarily a black thing" had the highest physical activity and were less likely to be overweight or obese, according to the study. "The notion is that if people identify with the activity, they are more inclined to participate in it," says the author. Given the high prevalence of obesity and other illnesses among women, research into the relationships between culture and exercise is "essential and timely." These health-related concerns are understudied among teenagers in particular. Due to its complexity and "multidimensionality." Durkheim, (1995) culture is intrinsically difficult to examine. "I believe that is the study's biggest challenge," he added, notwithstanding the challenge of understanding culture scientifically, provided an adequate explanation for their action. (Durkheim 1995). Physical activity is an important component of living a healthy lifestyle. Men, on the other hand, are more likely than women to be active in most nations (Crawford 2014). Women's levels of physical exercise might be influenced by cultural norms and customs (Birrell \& Cole 2014). There are frequently insufficient safe, inexpensive, and suitable programs and venues for girls and women to participate.

\section{Exercise Is Essential For Maintaining Excellent Health}

Noncommunicable illnesses such as cardiovascular disease, depression, breast and colon cancer, and type 2 diabetes can all be prevented with it. It isn't only about sports and games, though

(Hahn and Payne, 2015). Physical exercise is defined by the World Health Organization and UNICEF as "any physiological movement produced by skeletal muscle that needs energy expenditure." Physical exercise must be incorporated into people's daily lives, according to the WHO's Global Action Plan on Physical Activity 2018-2030. However, if cultural norms prevent it, this can be difficult.

\section{Influencing Factors In Recreational Sports Interest}

Recreational sports are major impacts on human physiology and psychology and play an essential role in our leisure activities. Exercise offers physiological benefits in terms of improving health and lowering death rates. Regular and moderate leisure sports lower the risk of diabetes, cardiovascular disease, and cancer, and are linked to a variety of death rates via correlations with health markers including Body Mass Index (BMI) (Shanunu et al. 2019). Individuals who engage in moderate-intensity exercises such as fast walking for 15 minutes daily, or 92 minutes weekly, in Taiwan, regardless of gender or cardiovascular disease status, benefit from a 14 percent lower mortality rate and a three-year extension in average lifespan compared to those who do not exercise at all, according to a study by Wenner (2018).

It is well acknowledged that sports engagement has several advantages, with studies demonstrating a clear link between increased participation in sports and higher academic achievement as well as enhanced physical and mental health. Following the worldwide suspension of amateur sport caused by the current Coronavirus pandemic, it is appropriate to examine the elements that influence sports participation in order to guarantee that any drop in participation is only temporary. How simple is it to surf or ski without snow if you don't live near the coast? While access is a constant challenge for participants in many sports and games activities, research shows that it isn't just a matter of investing in amenities, if the environment surrounding the physical amenity isn't conducive to getting there (for example, poor road lighting) or participating (for example, anti-social behaviour), new amenities can be underused. According to research by Hazel (2010), increasing investment in greenways, footpaths, and bike tracks around the country may have been a major role in making it simpler for individuals to get active. According to the same study, increased expenditure in facilities did not lead to increased involvement (other than those for cycling, walking and swimming). Sports groups have the potential to collaborate and share assets for the benefit of their local communities, and scheduling systems can aid with this, especially in regions with a large population and high demand.

\section{Role Models And Motivational Factors:}

Different sports have various features that appeal to various types and communities (Angela, 2001). Some people will be encouraged to participate in sports because of the physical and/or mental health advantages, which may be especially important in this age of social isolation. Others may appreciate the social contact that has been hampered by limitations. For others, it may be the opportunity to get outside, the competitive component of sport, or the desire to follow in the footsteps of a hero that inspires them (Chen et al 2017). Irish Women's Hockey's team recent success in reaching the World Cup final for the first time and qualifying for the Olympics is sure to increase interest in the sport. Katie Taylor, an Olympic boxing champion who also serves as an ambassador for women's sport in general, has had a similar impact, while Manchester United footballer Marcus Rashford has been a notable role model in the UK since the COVID-19 
outbreak, championing free meals for underprivileged school children. Ex-sports stars and TV role models who support national programs and community-focused sports shows (e.g., Operation Transformation / Ireland's Fittest Family) help to foster a culture of involvement and healthy living. Role models are often found much closer to home, and it's no wonder that siblings, children, and extended relatives of great athletes (at all levels) participate in sports as well. The myths and misconception that physical activities and sports participation allows females to become barren, roles models of like Belizean-American former world champion track and field athlete and a former professional basketball player for Tulsa Shock in the Women's National Basketball Association (WNBA). Marion Jones should be allowed to serve as a role model to female students. Marion Jones is blessed with three (3) kids.

Gender and age are key determinants in sports participation all around the world, and while they may be used alone to identify trends, when combined, they provide a fast picture of where participation is falling behind (Chen et al 2017). It's critical to establish the habit early and address drop-off rates for example, participation among teenage girls appears to be a recurring issue, as noted in this Sport Ireland report, which identifies the decline in post-primary girls' participation as an area of real concern, as indicated by Cortis and Muir (2016). Developing motor abilities at a young age and establishing a basic foundation of physical education through school provides a strong basis for increased engagement and fosters a positive attitude toward sport's worth. Whether or not physical education is required, there appears to be a drop in involvement during secondary school, which is especially noticeable among adolescent girls (Angela, 2001).

According to Shanunu, et al (2020), when sport becomes more competitive, a number of variables are at play, including shifting motives for participation, gender separation, conflicting interests and responsibilities, and a shortage of playing time. There is also evidence that parents who take sports too seriously destroy their children's love of the sport. Less encouragement from the sidelines means less pressure on children to "perform well" (Angela, 2001). Women's engagement in sports has been hampered by traditional gender stereotypes. This may significantly diminish the already limited chances for women to participate in sports (Adesoye, 2012).

Sport may boost self-esteem by providing chances for females to gain new abilities, form positive relationships, volunteer, and get public recognition. In contrast to the popular belief that sport is for everyone, most women face role conflict, which is mirrored in the public's perception of female engagement in sports (Adesoye, \& Apaak, (2013). Adesoye, \& Apaak (2013) States parties "recognize the right of the child to rest and leisure, to engage in play and recreational activities," according to article 31, paragraph 1 of the Convention on the Rights of the Child. Girls from rural and impoverished urban households, on the other hand, are saddled with domestic duties and child care from an early age, leaving them with little time to play.

Religion, Sports/Games, And Physical Activities:

Babatunde (2015) defined religion as a cultural universal characterized by a coherent system of beliefs and practices about sacred objects, connecting all individuals who adhere to such beliefs, values, and practices into a single moral community. Religion is a system of symbols, beliefs, values, and activities that focuses on ultimate meaning or questions. Many sports have emerged as part of religious celebrations in the past; Andrews agrees that sport is frequently used as a metaphor for religious endeavor (Andrews, 2017).

According to Andrews, (2017) sporting events elicit a strong emotional response akin to religious holidays Both religion and athletics use powerful symbols to communicate their messages. Some faiths and civilizations have regulations or expectations that make sports participation more challenging. These limitations disproportionately impact women and are frequently related to clothes. Boyle, et al (2017), because many faiths have set periods for rituals and worship, the time of day may have an impact on participation. The influence of religion on sports dress and scheduling (due to rituals / times of worship), as well as other issues such as ethnic visibility and diversity in coaching and volunteering, are now important concerns when they may have been overlooked or discriminated against in the past. However, government regulations, governing body initiatives, and club rules at the grassroots level are increasingly focusing on inclusiveness and removing barriers to participation (NaCCA, 2020). According to Andrews (2017), sports anecdotes can be utilized in sermons, although some congregations hope their preacher would never use another sports example, while others cannot get enough, as Cashmore (2015) concurred. Through sports camps, leagues, and coaching clinics, sports may also give chances for outreach to individuals in the community (Cashmore et al., 2015). One of the most efficient methods to interact with individuals from various cultures is via sports and activities. Sports can help us discover more about ourselves. When we lose our cool or cheat when competing in sports, it indicates a weakness in our character that needs to be addressed. Sports, like many other activities, can function as a Rorschach test for Christian character (Cashmore et al., 2015).

Sports evangelism is when sports are utilized as the primary medium for spreading the gospel (Tomlinson, 2012). Believers can adapt to the individuals they're attempting to reach with the gospel through sports evangelism. Although sports evangelism is not a conventional method of spreading the gospel, we all have unique skills that we are called to use in telling our stories or communicating with others (Romans 12:6-8). The message is not being altered; only the manner is being modified in order to reach more people. "In the first century, it was the roads of Rome that spread the gospel, but now it is sports that transport it" (Tomlinson, 2012. p. 279). Sporting activities are an important component of every culture, and they affect a large portion of the population on a 
yearly basis. Sports evangelism is based on the concept that sports give a platform for sharing the gospel that would otherwise be unavailable. This technique of preaching the gospel has grown in popularity to the point where many colleges are now offering degree programs in it: There are several types of sports evangelism (Tomlinson 2012). Competition centered: non-professional club level league competition, which some call to as recreational ministry. Significant event centered: covers most yearly professional sports activities, major collegiate events, and events such as the Olympics.

Islam teaches us to safeguard our mental, spiritual, and bodily well-being. As a result, it established several directives, suggestions, and rules for the protection and development of our bodies. Wrestling was one among the sports created by our beloved Prophet (PBUH), according to Hamidullah (2000). Our Prophet Mohammed (PBUH) wrestled with the wrestler Rukame several times and occasionally vanquished him, according to Diyanet (2014), (bni Hişam: I, 390-91). In all things, our beloved Prophet (PBUH) has urged his Ummah to be strong. The Prophet Mohammed (PBUH) emphasized the importance of physical growth. People have been sent to this earth to be tested, according to Islam. "A strong believer is better than a weak believer, and more loving to God," said our Prophet (pbuh). It is important to strengthen the body (Mishkat al-Meshbih, Hadith No: 5298.) Equestrianism is also one of the sports that the Islamic religion promotes. "We have created horses for you and for a trinket," Allah Almighty says in the Qur'an (Diyanet Yaynlar 2014). Muslims are permitted or even encouraged to enjoy games and sports in order to relieve the melancholy and sorrow of their fatigue in life, but they must adhere to Islamic laws and restrictions (www.diyanet.gov.) Sports and sporting activities in Islam implicitly ban social excitement, which must be disruptive, academic and professional, which must be morally upsetting, professionally working, which must be created grief, displaying sexuality, and wasting time (Salat 41, Buhari (2015); Ebu Dawud, (2011). Cihad no. 60. Enes Malik (2011). (Hadith Bukhari, number 452) There is nothing in the Quran or Hadith that expressly forbids men or women from engaging in physical activity as long as it does not conflict with their beliefs (Daiman 2011).

As a result, the "Accept and Respect" proclamation asserts that Islam is an enabling faith that allows women to engage in physical activities. The Hadith text provides several examples from the Prophet's (Mohammed, pbuh) life that may be utilized to encourage female and male involvement and equal opportunity.

It is well knowledge that Islam is a way of life that emphasizes the entire development of the human being, including spiritually, intellectual, and physical well-being. As a result, men and women are urged to live better lives in terms of their bodies, minds, and spirits. Swimming, shooting, and horseback riding were among the activities pursued by youngsters at the period. (Hadith-Caliph 634-44H, 20-
21Hadith-Caliph 634-44Hadith-Caliph 634-44 There is mention of the prophet (Mohammed, pbuh) racing with his wife, Aisha, as well as proof that some women battled with males, implying that they were physically strong fighters. Also, the prophet (Mohammed, pbuh) is believed to have stated, "Your lord has a right on you, your own self has a right on you, and your family has a right on you," therefore give all those who have rights on you, their rights. (Hadith Bukhari, number 452 In comparison to the more developed world counterparts, most developing nations, including Nigeria, have not seen rapid changes in women's active engagement in sports, according to Ikulayo (2018). This is due to a variety of socio-cultural elements such as religion, parenthood, culture, peer group, gender roles, and the impact of mass media on religion in northern Nigeria, for example.

\section{METHODOLOGY}

A survey research design was used to find out the Cultural/Customs and Traditional belief systems that affect participation of Females in Sports and games in Colleges of Education in Northern Ghana. The research is focused on prevailing beliefs systems, attitudes and relationship that exist between Cultural/Customs and Traditional belief systems and Participation of females in Sports and games.

\section{Population, Sample Selection and Sample Size}

Yin, (2009) opines that fields that can be researched into serves as a 'population 'Millar (2001) agrees that there is a need to select a few items from a large population for study purposes. This is to enable one to make inferences and to be able to generalize. The study area is the Colleges of Education in Northern region. The sampling technique used for the study was convenient sampling technique. It was preferred because respondents were conveniently and readily available. Not all the students were selected but only the female's students were randomly selected from the four (4) Northern colleges of Education.

\section{Data Collection and Analysis}

Collection of data is very important for any research process; data inaccuracy can hamper the reliability of the research (Ader, 2008) The Socio-Economics - Demographic Characteristics of a study population play a vital role in the collection of data. Data was collected from secondary and primary sources. The instrument used to gather the data was the open-ended and closed-ended questionnaire. Both qualitative and quantitative data analysis approaches were employed. The SPSS was used for the analyses and then quantified into simple statistical percentages.

\section{FINDINGS RESULTS AND DISCUSSIONS}

The study examined the socio-cultural, Physiological, Cultural/Customs, Traditional, religious doctrines, and gender constraints factors inhibiting female participation in sports in Colleges of Education in Northern Region. The case-study documentation and data collected were analyzed within the context of the stage model by Lin, (2016). The research 
instrument for this study was validated by three experts in the Department of Culture and Gender. In all 600 open-ended and closed-ended questionnaires were sent out to the (4) four colleges of education. The administered questionnaires were collected after two (2) days of completion and all the necessary information was duly entered by respondents. Out of the 600 questionnaires only 575 was retrieved, the analysis is based on the available data.

Table 1. Participation Influenced By Religious Beliefs/Norms

\begin{tabular}{|c|c|c|c|c|c|}
\hline ITEM & $\begin{array}{c}\text { AGRE } \\
\text { E }\end{array}$ & $\begin{array}{c}\text { STRONG } \\
\text { LY } \\
\text { AGREE }\end{array}$ & $\begin{array}{c}\text { DISAGR } \\
\text { EE }\end{array}$ & $\begin{array}{c}\text { STRONG } \\
\text { LY } \\
\text { DISAGRE } \\
\text { E }\end{array}$ & $\begin{array}{c}\text { DECLIN } \\
\text { ED TO } \\
\text { ANSWE } \\
\text { R }\end{array}$ \\
\hline $\begin{array}{c}\text { Do you } \\
\text { believe } \\
\text { that males } \\
\text { and } \\
\text { females } \\
\text { should } \\
\text { engage in } \\
\text { sports or } \\
\text { physical } \\
\text { exercise } \\
\text { together? }\end{array}$ & 121 & 93 & 302 & 49 & 10 \\
\hline $\begin{array}{c}\text { Should } \\
\text { women }\end{array}$ & 89 & 411 & 45 & 30 & \\
\hline
\end{tabular}

\begin{tabular}{|c|c|c|c|c|}
\hline $\begin{array}{c}\text { only } \\
\text { engage in } \\
\text { activities } \\
\text { or } \\
\text { exercises } \\
\text { that are } \\
\text { sanctionec } \\
\text { by their } \\
\text { religion? }\end{array}$ & & & & \\
\hline $\begin{array}{c}\text { Females } \\
\text { should be } \\
\text { permitted } \\
\text { to engage } \\
\text { in sports } \\
\text { and } \\
\text { physical } \\
\text { exercise at } \\
\text { any time } \\
\text { of day? }\end{array}$ & 318 & 50 & 176 & 31 \\
\hline $\begin{array}{c}\text { Do you } \\
\text { wish to } \\
\text { participate } \\
\text { in } \\
\text { sports/gam } \\
\text { es and } \\
\text { physical } \\
\text { exercise as } \\
\text { a female? }\end{array}$ & 391 & 167 & 17 & \\
\hline
\end{tabular}

Field data: 2021

Fious beliefs

Figure 1. Religious beliefs 
Religious Customs Prohibit Women From Participating In Sports?

In contrast to the expectation that sport be enjoyed by all, women face role conflict, as evidenced by the findings, which show that $92 \%$ of respondents agree that religion has an impact on sports participation in Northern Region colleges of education. According to Marta and Steve (2013), women are more religious than men. Despite being barred from leadership roles, women are more likely than males to pray, worship, and state that their faith is vital to them in practically every cultural and religious tradition. They also dominate the realm of 'New Age' spirituality and are significantly more superstitious than men. Only eight $(8 \%)$ disagree and others declined.

\section{Participating In Sports Exposes Ladies' Sensitive Areas?}

Table 1 indicates that $554(96 \%)$ of the female respondents in the four (4) Northern region colleges of education strongly agreed that they will not participate in physical activities, sports and games because of exposer of their body parts to men or public which is against their religious privacy. This result goes a long way to defeat the purpose of National Council for Curriculum and Assessment - Ghana (2020) government regulations, governing body initiatives, and club rules at the grassroots level which focus is to increase, inclusively removing barriers to participation in physical activities, sports and games in schools. But the findings support Ikulayo (2018) who concur that a variety of sociocultural elements such as religion, parenthood, culture, peer group, gender roles, and the impact of mass media has an impact on physical activities, sports and games.

Do you believe that males and females should engage in sports or physical exercise together? Sports and religion are, in comparison, inextricably interwoven. Sports, like religion, teach crucial lessons about values and how to behave in a culturally appropriate manner. Both religion and athletics use symbols as their major means of communication, and the teachings they teach are comparable. Table 1 shows that $61 \%$ (351) of females prefer to participate in sports, games, and physical activities alone rather than in groups with their male counterparts. Only 37\% (214) agreed that they would like to participate in sports, games, and physical activities with their male counterparts. Females who engage in solo gaming, sports, and physical activities have better levels of confidence and self-esteem and lower levels of depression (Hums 2018). The findings are in consonance with Hums (2018) who observed that Females who play sports have a more positive body image and experience higher states of psychological well-being. Sports, physical exercise, and recreational activity contribute to our development as spiritual beings composed of body and soul.

\section{Should Women Only Engage In Activities Or Exercises That Are Sanctioned By Their Religion?}

Religion is frequently viewed as an impediment to gender equality, Ademiluka, (2017). In general, Islam advocates excellent health and fitness, and both men and women are encouraged to participate in physical activity in order to live a healthy lifestyle. However, there are components of religion that limit how sports can be conducted, such as women following their faith being unable to participate in mixed gender sports, as well as the setting, gender stereotypes, and clothing code (Women's Sport and Fitness Foundation 2011). The study revealed that $500(87 \%)$ of the respondents will like females to participate in sports, games and physical activities that are sanctioned by their religious faith. The data back up the assertion made by the Women Sports and Fitness Foundation (2011). Only 75 (13\%) disagree with the statement. This also suggests that women are more devoted and adhere to their religious beliefs.

Females Should Be Permitted To Engage In Sports And Physical Exercise At Any Time Of Day?

Bodily activity is beneficial to all of us in a variety of ways, including physical, mental, psychological, and social advantages. Females, on the other hand, often lose out on the active play, exercise, and sport engagement that would improve their health, confidence, self-esteem, and ability to cope with stress (Willis, 2016). Table 1 demonstrates that $64 \%$ (368) of females would prefer more time to participate in sports, games, and physical activities at any time. But because many faiths have defined times for rituals and worship, the time of day may have an impact on participation as opined by Boyle, et al (2017). Religion's impact on sports attire and scheduling. Only 207 of the respondents representing 26\% disagree to the statement.

Do You Wish To Participate In Sports/Games And Physical Exercise As A Female?

Regular physical activity is vital for good physical and mental health. It helps improve your overall health and fitness, maintain a healthy weight, reduce your risk for many chronic diseases and promote good mental health. The findings suggest that despite religious constrains females are still willing to participate in sports, games and physical activities. the results indicates that 558 respondents representing $97 \%$ agreed that they wish to take part in physical activities. This also indicates that females know the benefits of physical activities to the feminist body. The willingness of the females to accept to do physical activities regardless of religion confirms research by Women's Sport and Fitness Foundation (2011). Only 17 (3\%) disagree to the statement.

\section{Influence Of Gender Constraints On Sports/Games And Physical Activity:}

The study revealed that the positive outcomes of sport for gender equality and women's empowerment are constrained by gender- based discrimination in all areas and at all levels of sport and physical activity, fueled by continuing stereotypes of women's physical abilities and social roles. Women are frequently segregated involuntarily into different types of sports, events and competitions specifically targeted to women. Women's access to positions of leadership and 
decision-making is constrained from the local level to the international level in sports, games and physical activities. The value placed on women's sport is often lower, resulting in lack of participation. In general, men tend to practice sports or other physical activities more often than women in the European Union. For instance, $45 \%$ of men exercise or play sport at least once a week, whereas $37 \%$ of women do so (Babatunde, 2015). It was also revealed that Lack of time, lack of knowledge, encouragement from the parents and family members, family problems and lack of money and companion, are indicated as the most significant recreational constraints in the way of female participation in sport. Sports has the most gender inequality (Babatunde, 2015). Some Teachers were also mentioned in that they do not like the participation of females in sports activities, they think that sports activities are only leisure time activities and wastage of time and students cannot make balance between academic activities and sports activities and that female students should concentrate on only their academic activities and just focused on their homework.

The findings agree with Zimmerman, and Reavill, (2013) who opined that, the positive outcomes of sport for gender equality and women's empowerment are constrained by gender- based discrimination in all areas and at all levels of sport and physical activity, fueled by continuing stereotypes of women's physical abilities and social roles. Women are frequently segregated involuntarily into different types of sports, events and competitions specifically targeted to women. Females easily identify with female coaches, who can fight negative cultural messages and show Females that they belong in sports Adler, (2018) concluded.

Table 2. Influence Of Cultural Practice On Sports/Games And Physical Activity

\begin{tabular}{|c|c|c|c|c|c|}
\hline ITEM & $\begin{array}{c}\text { AGRE } \\
\text { E }\end{array}$ & $\begin{array}{c}\text { STRONG } \\
\text { LY } \\
\text { AGREE }\end{array}$ & $\begin{array}{c}\text { DISAGR } \\
\text { EE }\end{array}$ & $\begin{array}{c}\text { STRONG } \\
\text { LY } \\
\text { DISAGRE } \\
\text { E }\end{array}$ & $\begin{array}{c}\text { DECLIN } \\
\text { ED TO } \\
\text { ANSWE } \\
\text { R }\end{array}$ \\
\hline $\begin{array}{c}\text { Is it } \\
\text { against } \\
\text { your } \\
\text { cultural } \\
\text { beliefs to } \\
\text { engage in } \\
\text { sports and } \\
\text { physical } \\
\text { exercise as } \\
\text { a woman? }\end{array}$ & 280 & 100 & 78 & 51 & 66 \\
\hline $\begin{array}{c}\text { Do you } \\
\text { believe it } \\
\text { is } \\
\text { inappropri } \\
\text { ate for } \\
\text { women to } \\
\text { engage in } \\
\text { sports and } \\
\text { physical } \\
\text { activity? }\end{array}$ & 134 & 283 & 110 & & \\
\hline $\begin{array}{c}\text { Is } \\
\text { culturally } \\
\text { acceptable } \\
\text { for girls }\end{array}$ & 98 & 57 & 314 & & \\
\hline
\end{tabular}

\begin{tabular}{|c|l|l|l|l|l|}
\hline $\begin{array}{c}\text { and boys } \\
\text { to engage } \\
\text { in sports } \\
\text { and } \\
\text { physical } \\
\text { exercise } \\
\text { together? }\end{array}$ & & & & & \\
\hline $\begin{array}{c}\text { As a } \\
\text { female, i } \\
\text { watch } \\
\text { sports } \\
\text { programs } \\
\text { on TV at } \\
\text { home? }\end{array}$ & 34 & 76 & 298 & 120 & 47 \\
\hline $\begin{array}{c}\text { Do you } \\
\text { want } \\
\text { indigenous } \\
\text { games to } \\
\text { be played } \\
\text { only by } \\
\text { women? }\end{array}$ & 312 & 111 & 59 & 37 & \\
\hline
\end{tabular}

Field data: 2021

Table 2 revealed that, cultural beliefs had an impact on female participation in sports/games and physical activity, 280 of the respondents agreed and 100 respondents strongly agreed to the statement representing $66 \%$ cumulatively of the total respondents. This finding goes to support Birrell and Cole (2014) who opined that Women's levels of physical exercise might be influenced by cultural norms and customs. On the accession that culturally is inappropriate for women to engage in sports and physical activity? 417 respondents agree and strongly agree to the statement. An indication of how sensitive women are in terms of their cultural heritage, 110 of them disagree. Acceptability of women and men to engage in sports and physical exercise together? Women who are active in sports and recreational activities as girls feel greater confidence when alone, self-esteem and pride in their cultural, physical and social selves than when mixed with men as agreed by Angela (2001). Half of all girls who participate in some kind of sports experience higher than average levels of self-esteem and less depression when they play alone, she added. The research revealed that $314(55 \%)$ of the respondents disagree. From the table above, cumulatively 418 $(73 \%)$ of the respondents disagree to the statement that they do watch sports programmes on TV. Only 19\% agreed to the statement. This can be attributed to Ugwueze (2014), certain societies assign specific responsibilities to men and women. Women in our traditional society are mostly educated at home to become good housewives and mothers (Ugwueze, 2014). The respondents that refused to comment about it was $8 \%$. The table above shows that $74 \%$ of females will prefer playing more indigenous games. Culturally, females are seen to be quiet, obedient and attractive nurturers. Traditional Indigenous games taught valuable skills but also combined mental and physical wellbeing as indicated by Bob (2019). Culturally, females are expected to wear dresses, cook and clean, raise children, maintain a beautiful and delicate body, and remain passive, moral, and pure (Zimmerman and Reavill, 2013). This means that, majority of the respondents agreed 
that cultural beliefs of respondents had significant influence on female participation in sports.

Table 3. Physiological dimensions

\begin{tabular}{|c|c|c|c|c|c|}
\hline ITEM & $\begin{array}{c}\text { AGRE } \\
\text { E }\end{array}$ & $\begin{array}{c}\text { STRONG } \\
\text { LY } \\
\text { AGREE }\end{array}$ & $\begin{array}{c}\text { DISAGR } \\
\text { EE }\end{array}$ & $\begin{array}{c}\text { STRONG } \\
\text { LY } \\
\text { DISAGRE } \\
\text { E }\end{array}$ & $\begin{array}{c}\text { DECLIN } \\
\text { ED TO } \\
\text { ANSWE } \\
\text { R }\end{array}$ \\
\hline $\begin{array}{l}\text { Do you } \\
\text { think you } \\
\text { could be } \\
\text { hurt when } \\
\text { doing } \\
\text { physical } \\
\text { activity? }\end{array}$ & 458 & 47 & 24 & 40 & 6 \\
\hline $\begin{array}{c}\text { I do engage } \\
\text { in any } \\
\text { physical } \\
\text { activities } \\
\text { when } \\
\text { menstruati } \\
\text { ng? }\end{array}$ & 41 & 34 & 371 & 121 & 8 \\
\hline $\begin{array}{l}\text { Is it true } \\
\text { that being } \\
\text { physically } \\
\text { active } \\
\text { makes you } \\
\text { barren? }\end{array}$ & 402 & 105 & 51 & 17 & \\
\hline $\begin{array}{c}\text { Isn't it true } \\
\text { that a } \\
\text { woman's } \\
\text { body isn't } \\
\text { as well- } \\
\text { developed } \\
\text { as a man's } \\
\text { when it } \\
\text { comes to } \\
\text { engaging in } \\
\text { physical } \\
\text { activity? }\end{array}$ & 410 & 115 & 50 & & \\
\hline
\end{tabular}

Field data: 2021

Judging from Table 3, the results indicates that, 505 women $(88 \%)$ believe that fear of injury prevents them from participating in physical/sporting and games activities. Only $11 \%$ of the people polled disagree. Meanwhile, $1 \%$ of them refused to respond to the question. Table 3 also revealed that 492 (86\%) female students do not participate in physical/sporting activities during their menstruation, which has a substantial impact on female students' involvement in sports/games activities at colleges of education in the Northern Region. Many studies have shown that intensive exercise produces oligomenorrhea and amenorrhea in athletes, while moderate activity was linked to a slightly higher likelihood of prolonged cycles, as unfavorable side effects of exercise that outweigh the benefits (Kathleen, 2013). The veins of the uterus are naturally clogged during menstruation and are prone to rupture readily, according to Dasharathy et al, (2012). During menstruation, the vaginal walls expand as well. This is completely natural and explains the dull ache in the vaginal area during menses. Only $75 \%$ of females said when mensurating they don't engage in physical activity. (13\%) say that they engage in physical activity during menstruation or when participating in physical/games/sporting activities at school. Is it true that exercising regularly renders you barren? According to the research, 507 (88\%) of the females believe that participating in physical/games/sporting activities at school will render them infertile. The findings back up Andrews' (2017) assertion that girls require role models in order to participate in physical/games/sporting activities in college. Isn't it true that when it comes to physical exercise, a woman's physique isn't as well-developed as a man's? According to the table, 525 ladies (91\%) believe that their physiological appearance or body buildup is a difficulty that prevents them from engaging in sports/games and physical activities. Female athletes are generally underrepresented in sports media compared to male athletes. Furthermore, sportswomen are frequently stereotyped, comic, sexualized, and sexist. More often than not, their athletic skill is overshadowed by their physical attractiveness, femininity, and/or sexuality. Men and women have different exercise routines and motivations, according to research (Tiggemann \& Williamson, 2010; Lustyk et al., 2014).

\section{Influence Of Traditional/Custom Belief Systems On Women:}

The results indicated the following in reaction to traditional/customary beliefs systems on women's engagement in sports, games, and physical activity: Women's access to information is limited by strict customs observation, myths, curses and taboos based on effects on their reproductive organs, and women lose their femininity through active participation in sports, female genital mutilation, and women cleansing are some of the belief systems that contribute to women's low participation in sports/games and physical activity. This finding is consistent with Babatunde's (2015) findings, which stated that physiological myths, taboos, traditional and custom beliefs are strong in some societies, which many people still believe in, and physical exercise by women has a detrimental common characteristic in patriarchal systems, which relegate women to a class much lower than the average man in terms of participation in sports.

\section{Sociological Dimensions:}

Regular physical activity is vital for good physical and mental health. Regular physical activity can improve women's health and help prevent many of the diseases and conditions that are major causes of death and disability for women around the world. The study indicated that there were sociological factors that influenced females' participation in sports, games and physical activities. Respondents agreed on the following; Fear of being judged by others based on their appearance, fear about their ability to take part and fear of judgement for choosing to spend time on themselves rather than on their families, persistence of stereotyping of women, lack of time, a lack of appropriate, safe and accessible infrastructure, and no adequate clothing. This shows that while parents tend to permit males, they object to females' participation in sport for sex stereotypic reasons. Similarly, males are more encouraged to participate in active pursuits of sports outside the home while female are reinforced for engaging in activities within the confines at home. According to Adeyanju, (2015) the low rate of women involvement in sports is not due to lack of 
interest in sports by them. Instead, it is due to the long history of direct and indirect forms of discrimination and stereotyping that woman have to contend with. The findings also corroborate Money (2012) who pointed out that, in France and many other countries, the Catholic and Protestant Churches opposed women's participation in sports. Similarly, it is a common belief by Nigerians that Islam discouraged adherents of Islamic religion from sport participation because of the specific types of dress that are prescribed for the participants and some societal influences.

\section{CONCLUSION AND RECOMMENDATIONS}

The outcome of this study has identified some of the Cultural/Customs, Traditional and other factors that influence female participation in sports/games and physical activities. The study has also identified that there is a significant link between Cultural/Customs and Traditional beliefs systems in the participation of females in sports/games and physical activities. The results have laid credence to Adeyanju (2015) who submitted that, the low involvement of women in sports is not due to the lack of interest in sports by women. It is due to the long history of direct, and indirect forms of traditional and cultural beliefs discrimination and stereo-typing as well as many other problems that women have to contend with. Arising from the findings of this study, the following are recommended: Use of enlightenment programmes that will demystify all Cultural/Customs and Traditional belief systems and biases against female participation in sporting, games and physical activities in our communities. The private organizations and individuals in the society should support the government at all levels to provide and encourage Cultural/Customs and Traditional games and physical activities in our communities. Enact legislations in schools and communities to enable more female participation in sports, games and physical activities. Changed legislations to allow sport/games for all and adequate infrastructure to permit easy and safe access and privacy in changing rooms and in facilities. Providing scholarship and other incentives to female athletes who excel in Cultural/Customs and Traditional games.

\section{REFERENCES:}

[1] Ader, Herman J (2008) Research Methodology in the Social, Behavioural and Life Sciences Amsterdam, Netherlands SAGE publishers

[2] Ademiluka, S.O., (2017), Issues at stake in the contemporary Nigeria church, NATHDEX, Ilorin.

[3] Adesoye, A. A. (2012). Perceived Limitations of Female Participation in Sports in Institutions of Learning. A Paper Presented at WAUG. University of Ilorin. Ilorin, Nigeria.77-80.

[4] Adesoye, A. A., \& Apaak, D. (2013). Senior high school students' perception of the effects of sports participation on academic performance in Central Region, Ghana. A Research Paper presented at the 2013 CEFWA International Conference at the University of Cape Coast, Ghana

[5] Adeyanju, F.B. (2015). Women and sports in Nigeria: problems and prospects in the 21stcentury. Available at http://www.onlinenigeria.com.accessed on 27-12-2015.

[6] Adler, J. (2018) Social changes and women in African sports. A Publication of Journal of social sciences. 2(1), 50-53.
[7] Andrews, D. L. \& Jackson, S. J. (Eds.) (2014) Sport Stars: The Cultural Politics of Sporting Celebrity. Routledge, New York.

[8] Angela Lumpkin (2001) Physical Education and Sports a contemporary introduction. $4^{\text {th }}$ Ed. Boston, WCB/McGraw-Hill

[9] Appiah-Opoku S (2007). Indigenous beliefs and environmental stewardship: a rural Ghana experience. Indigenous Knowledge and Development Monitor, 7(3):15-17.

[10] Babatunde, S.O. (2015). Socio-cultural Perspectives of Sports Participation. Ilorin Journal of Health Physical Education and Recreation, 5 (2) 43-49. Benchmark Journals

[11] Bernstein, A. \& Blain, N. (Eds.) (2013) Sport, Media, Culture: Global and Local Dimensions. Frank Cass, London.

[12] Birrell, S. \& Cole, C. L. (Eds.) (2014) Women, Sport, and Culture. Human Kinetics, Champaign, IL

[13] Birrell, S. \& McDonald, M. G. (2016) (Eds.) Reading Sport: Critical Essays on Power and Representation. Northeastern University Press, Boston.

[14] Bob Joseph, 2019 Dispelling Common Myths About Indigenous Peoples Published July 23rd 2019 by Beacon Press (first published July 1st 2019) Bolivia Amazon

[15] Boyle, R. \& Haynes, R. (2017) Power Play: Sport, the Media and Popular Culture. Pearson Education, Harlow.

[16] Buhari (2015): Salat 41; Ebu Davud (2011). Cihad 60. Malik b. Enes (2011). Cihad 45.

[17] Carroll, Bob and Hollinshead, G (2018) 'Ethnicity and conflict in physical education.' British Educational Research Journal, 19(1),59-76.

[18] Cashmore, E. (Ed.) (2015) Sports Culture: An A Z Guide. Routledge, London.

[19] Chen C, Tsai L-T, Lin C-F, Huang C-C, Chang Y-T, Chen R-Y, et al. (2017) Factors influencing interest in recreational sports participation and its rural-urban disparity. PLoS ONE 12(5): e0178052. https://doi.org/10.1371/journal.pone.0178052

[20] Coalter, F. (2017). A wider social role for sport: Who's keeping the score? Abingdon, UK: Coast, Ghana

[21] Cortis, N., Sawrikar, P., \& Muir, K. (2016). Participation in sport and recreation by culturally and linguistically diverse women. Discussion Paper. Report for the Australian Government Office for Women, SPRC Report 4/07, University of New South Wales

[22] Cox, E. (2014). A truly civil society. Sydney, Australia: ABC Books.

[23] Crawford, G. (2014) Consuming Sport: Fans, Sport and Culture. Routledge, New York.

[24] Daiman (2011) Women, Sports and Islam. Sport 2, 14-15. London: Routledge.

[25] Dasharathy SS, Mumford SL, Pollack AZ, Perkins NJ, Mattison Wactawski-Wende J, (2012) Menstrual bleeding patterns among regularly menstruating women. American Journal of Epidemiology.;175:536-45.

[26] Diawuo, F., \& Issifu, K. A. (2015). Exploring the African traditional belief systems in natural resource conservation and management in Ghana. The Journal of Pan African Studies, 8, 115-131.

[27] Diyanet Yayınları (2014). Kuranı Kerim Nahl, 8.

[28] Durkheim, Emile. (1995). The Elementary Forms of Religious Life. New York: Free Press.

[29] Duxbury N, Cullen C, Pascual J et al (2015) Cities, culture and sustainable development. In: Anheier HK, Isar YR, Hoelscher M et al (eds) Cultural policy and governance in a new metropolitan age. The cultures and globalization series, vol 5. Sage Publications Ltd, London, pp 73-86 Hadith Bukhari: (452)

[30] Hahn, Payne, Wayne, A and, Dale, B. (2015). Understanding your health Boston; MacGraw-Hill

[31] Hamidullah (2000). Muhammed., İslam Peygamberi, (çev:Salih Tuğ), İstanbul.

[32] Hanlon, C., \& Coleman, D. (2016). Recruitment and retention of culturally diverse people by sport and active recreation clubs. Managing Leisure, 11(2), 77_95.

[33] Hargreaves, J. (2015). Heroines of sport: The politics of difference and identity. London, UK: Routledge 
[34] Hargreaves, J. (2016) Sport, Power and Culture. Polity Press, Cambridge.

[35] Hazel Maxwell, (2010) School of Leisure, Sport \& Tourism, University of Technology, Sydney,

[36] Holy Bible, New International Version®, NIV® Copyright (C) $1973,1978,1984,2011$

[37] Idowu, B. (2016). OLÓDÙMARÈ: God in Yoruba Belief, Ibadan: Longman Nigeria

[38] Hums, M.A. (2018). Roles and status of women in sport management. Journal of the International Council for Health, Physical Education, Recreation, Sport and Dance, 34 (2), 12-13.

[39] Ikulayo, P.B. (2018). Psychological Issues in Female Participation in Sport. Journal of the International Council for Health, Physical Education, Recreation, Sport and Dance, 34 (3), 60-62.

[40] Johnson, A.G. (2005) The gender knot, unraveling our Patriarchal legacy, London university press

[41] Kahan, D. (2013). Islam and physical activity: Implications for American sport and physical educators. Journal of Physical Education, Recreation and Dance, 74(3), 48_54.

[42] Katherine A. Ahrens, (2013) Nov 15. doi: 10.1016/j.annepidem.2013.11.002 (https://www.ncbi.nlm.nih.gov/pmc/articles/PMC3946734/)

[43] King, A. (2013) The European Ritual: Football in the New Europe. Ashgate, Aldershot.

[44] Klafs, e. E. \& Arnheim, DoD. (2013). Modem principles of Athletics training. St. Louis: e.V. Mosby

[45] Lin, N. (2016). Social capital: A theory of social structure \& action. NY: Cambridge University Press.

[46] Lustyk MKB, Widman L, Paschane AE, Olson KC. (2014) Physical activity and quality of life: Assessing the influence of activity frequency, intensity, volume and motives. Behavioral Medicine.;30:124-131.

[47] Marta Trzebiatowska and Steve Bruce (2013). Why are Women more Religious than Men? Published to Oxford Scholarship. Oxford University Press

[48] Martin, R. \& Miller, T. (Eds.) (2015) SportCult. University of Minnesota Press, Minneapolis.

[49] Maxwell, Hazel and Taylor, Tracy (2010) 'A Culture of Trust Engaging Muslim Women in Community Sport Organizations', European Sport Management Quarterly, 10: 4, 465 — 483

[50] Mc Laughlin, L., \& Braun, K. (2018). „Asian and Pacific Islander cultural values: Considerations for health care decision-making. "Health and Social Work, 23 (2), 116-126.

[51] Miller, T. (2001) Sportsex. Philadelphia, Temple University Press.

[52] Miller, T., Lawrence, G., McKay, J., \& Rowe, D. (2011) Globalization and Sport: Playing the World. Sage, London.

[53] Money, E.O. (2012). A study of the perception of female athletes towards female coaches. Journal of Sport Science and Medicine, 3(2), 94-96 Muslim Women in Sport, Women's Sport and Fitness Foundation and Sporting Equals, January 2017 Müslim, İmaret: 168; Ebu Davud, Cihad, 23-68.

[54] National Council for Curriculum and Assessment (NaCCA) (2020). Ministry of Education. Ghana

[55] New Zealand Ministry for Culture and Heritage (NZMCH), cultural well-being. WellingtonNZMCH (2016) Cultural wellbeing and local government report 1: of Learning. A Paper Presented at WAUG. University of Ilorin. Ilorin, Nigeria.77-80.

[56] Osei J., (2012). The Value of African Taboos for Biodiversity and Sustainable Development.www.jsd- africa.com, July 20,

[57] Palmer, C. (2015). A world of fine difference: Sport and newly arrived young refugee women in Adelaide. Study presented to Department of Gender Studies, University of Otago, New Zealand, Paper presented at the 2013 CEFWA International Conference at the University of Cape

[58] Renn E. \& Sirleaf, E. J. (2012) Women, War and Peace; The Independent Experts' Assessment on Impact of Armed Conflict on Women and Women's Role in Peace- Building; UNIFEM, New York.

[59] Roche, M. (2017) Mega Events and Modernity: Olympics and Expos in the Growth of Global Culture. Routledge, New York.
[60] Routledge. Coffe, H., \& Geys, B. (2015). Toward an empirical characterisation of bridging and bonding social capital. Nonprofit and Voluntary Sector Quarterly, 36(1), 121139.

[61] Rowe, D. (2015) Popular Cultures: Rock Music, Sport and the Politics of Pleasure. Sage, London.

[62] Rowe, D. (2004) Sport, Culture and the Media: The Unruly Trinity, 2nd edn. Open University Press, Maidenhead.

[63] Sfeir, L. (2010). The status of Muslim women in sport: Conflict between cultural tradition and modernization. International Review for the Sociology of Sport, 20(4), 283_306.

[64] Shanunu Zakaria, (2019) Use of Body Mass Index (BMI) to Determine Cardiovascular Risk Factors of Physical Education Teachers in Tamale Metropolis. Journal of Educational Development and Practice. VL 3, No 3. UCC Press. Cape Coast Ghana.

[65] Shanunu Zakaria, Iddrisu Sulemana, Alhassan Imoro Nuhu (2020) Determining Participating Factors in Physical Education/Sporting Activities of the Deaf: A Study of Savelugu School for the Deaf, Issue: Vol.1 No.1 May 2020 Article 3 pp.18-28 DOI : NAYOM Journal of Education and Learning Technology (JELT) - Published online 27th August 2020.

[66] Tansin , B. Gertrud, Pfister and Haifaa Jawad (2011) Muslim Women and Sports. Routledge, Taylor \& Francis group. London, New York

[67] Throsby, D. (2011). The Economics of Cultural Policy; Cambridge University Press: Cambridge, UK,

[68] Tiggemann M, Williamson S. (2010) The effect of exercise on body satisfaction and self-esteem as a function of gender and age. Sex Roles.;43:119-127.

[69] Tomlinson, A. (2012) The Game's Up: Essays in the Cultural Analysis of Sport, Leisure and Popular Culture. Ashgate, Aldershot.

[70] Ugwueze, F.e. (2014). Some constraints to women's full participation in sports in Nigeria. In E.N. Okpara (Ed) Gender issues in education and development: A book of reading (pp. 41 56) Nsukka: University Trust Publishers.

[71] Vera Kurian (2014) Never Saw Me coming. Harper Collins publishers. New York

[72] Walseth, K. (2016). Young Muslim women and sport: The impact of identity work. Leisure Studies, 25(1), 75_94. New York.

[73] Wenner, L. A. (2018) Media-Sport. Routledge, New York.

[74] Whannel, G. (2001) Media Sport Stars: Masculinities and Moralities. Routledge, London.

[75] Whannel, G. (2013) Fields in Vision: Television Sport and Cultural Transformation. Routledge, London.

[76] Willis, P. (2016) Women in Sport in Ideology. In J. Hargreaves (ed) Sport, Culture and Ideology. London, UK: Routledge and Kegan Paul.

[77] Women's Sport and Fitness Foundation. (2011). Muslim women in sport. Retrieved November 17, 2011, from http://www.wsff.org.uk/documents/Muslim women in sport.pdf.

[78] World Health Organization and UNICEF. Progress on drinking water and sanitation: special focus on sanitation. www.aifs.gov.au/cafca/ppp/docs.CCCH-early-childhood.pdf

[79] Wuest D.A and Bucher C.A (2001) Foundations for Physical Education and Sports. Boston, WCB/McGraw-Hill

[80] www.diyanet.gov.tr/tr/icerik/islamda-spor/6413 Mart 2015.

[81] Yin, R.K. (2009). Case study research: Design and methods (4th ed.). Los Angeles: Sage.

[82] Zimmerman, J. and Reavill, G. (2013). Raising Our Athletic Daughters: How Sports Can Build Self-Esteem and Save Girls' Lives. Doubleday: New York. 